\title{
The Role of Written Feedback in Numeracy in the Primary School Classroom
}

\author{
Mutendi Miedzo ${ }^{1} \&$ Makamure Chipo, $^{2, *}$ \\ ${ }^{1}$ Paston Ridings Primary School, Paston Ridings, PE4 7XG, Peterborough, England \\ ²Belvedere Technical Teachers' College, 1 Harvard road, Belvedere, Harare, Zimbabwe \\ "Corresponding author: Belvedere Technical Teachers' College, Harvard road, Belvedere, \\ Harare, Zimbabwe. E-mail: makamburec@gmail.com
}

Received: March 25, 2019 Accepted: April 11, 2019 Published: April 30, 2019

doi:10.5296/ije.v11i2.14550ＵRL: https://doi.org/10.5296/ije.v11i2.14550

\begin{abstract}
This study seeks to establish the quality and type of feedback necessary and suitable for learners, understandable by learners and implementable in the learning process by the learners to improve progress in learning numeracy. However, although written feedback is believed to be instrumental in shaping the pupils' classroom performance, there is less agreement on whether this is workable in the real world of the classroom or has remained an intended goal of feedback. There is limited work in literature on how pupils respond or use written feedback to improve their performance. A questionnaire was administered to a group of Year 5 students at a school in England to solicit the pupils' perceptions of the usefulness of written feedback and the challenges that were likely to be faced in interpreting and implementing the feedback. In order to measure the impact of feedback on students' performance, a pre-test was given, pupils' recommendations from the questionnaire were incorporated, and a second test was given two days later. The two sets of marks were then compared. It was found that pupils find it difficult to understand written feedback at times, mainly because of unfamiliar vocabulary used in the feedback and when they do understand the language, they often find it unhelpful in achieving their learning goals. Teachers are recommended to simplify and add more detail to feedback, making it as informative as possible about what was done well and suggest improvements that could be made.
\end{abstract}

Keywords: Written Feedback, Instruction, Teaching, Learning, Learners, Numeracy 


\section{Introduction}

Feedback is at the centre of all the prominent teaching methods and techniques. A study by Glasgow and Hicks (2009) has shown a positive correlation between the amount of feedback given and improvement in the pupils' performance. In the same vein, the Higher Education Funding Council for England (2011) and James, Krause, and Jennings (2010), endorsed the role of feedback to the learners as valuable. Ferguson (2011) concurred that the issue of feedback is fundamental to a learner as it promotes independent learning. Due to this independent learning, Fergusson avers that learners are able to evaluate, monitor and regulate their own learning. Written feedback, at its very best, is an on-going, two-way dialogue between the teacher and pupils, and it should be visible, regular and continual (South Hansley School, 2013). These assertions are supported by the Ofsted Inspection Report (2018), which acknowledged written feedback as an interaction between the teacher and pupils, a way of acknowledging pupils' work, checking the outcomes and making decisions about what teachers and pupils need to do next. The facts alluded to above highlight the important role of feedback and the need for practitioners to ensure that they establish the best way to effectively communicate with learners (Clarke 2001). However, according to scholars, such as Knight (2016), Nicol (2010) and Orrella (2006), several studies about feedback across the world have questioned the quality of much of the feedback currently being given to learners. Most studies, according to Knight (2016), concur that the use of feedback to improve understanding was not realised in practice, citing that teachers often give feedback casually, without giving due consideration to its usefulness in helping pupils achieve their learning goals. Hence Conn (2002) avows that effective feedback should be based on observable behaviour and not on assumed intentions or interpretations, implying that feedback should be put into effect. Thus, a powerful and constructive feedback is considered as being strongly influential on student achievement, (Knight, 2016).

There is however, debate on what constitutes good teacher feedback in terms of quality. According to Knight (2016), literature reveals conflicting views about the type and quality of feedback given to the students. Hence, Hattie and Timperley (2007) concur that the type and quality of feedback makes feedback differentially effective to the learners. Nevertheless, The Educational Endowment Foundation (2015) left the discretion of determining any specific frequency, type or volume of feedback given to the students, to be decided by the school through its assessment policy. Regardless of the extensive feedback provided on every piece of work by the teachers, the Department for Education (2017) ascertained that there is little evidence that the feedback improves pupils' achievement in the long run. This view leads to the question on how learners value and respond to the teachers' written feedback to enhance their learning. These findings and other related studies show that the study on written feedback is not yet conclusive, and the study on mathematics teachers' feedback practices is not quite definitive (Knight, 2016). The researchers were hence, prompted and motivated to carry out this study which leans very much on the students' perceptions and experiences of written feedback. The study therefore seeks to contribute to the debate of feedback effectiveness by attempting to ascertain ways in which written feedback can impact on pupils' learning and how it can be improved to enhance conceptual understanding of numeracy among Year 5 students 
at a primary school in England. The following research questions guided the study:

What role does written feedback play in the children's classroom performance?

How do children respond and use the written feedback in their school work?

What can be done to improve written feedback to assist children make progress in learning numeracy?

\section{Literature Review}

\subsection{Pupils' Interest in Written Feedback}

Whilst the quality and type of feedback provided by the teacher is pivotal for students' achievement, Murphy and Cornell (2010) assert that the value attached to the feedback by the learners and what the learners do with it is more important. According to Nicol (2009), no matter how much feedback the instructor delivers, pupils will not benefit unless they pay attention to the feedback, process it and ultimately act on it. Contrary to the learners' practices, the assumption when some teachers give feedback may be that pupils will take notice, read and respond accordingly. But Knight (2016) avers that teachers' feedback in most cases lacks depth, is not well thought out, is difficult for pupils to understand, and many students do not attend to it at all. Knight's view suggests that sometimes pupils ignore or overlook the teachers' written feedback, hence the latter's efforts become fruitless. This view is collaborated by Brown (2001) and Gibbs and Simpson (2002), who concur that feedback provided by the teacher is not understood or is often not read at all by the learners. These revelations should be a wake-up call for teachers to remember that during classroom instruction, it is critical for them to take cognisance of the learners' views, opinions and perceptions about the feedback provided by the teachers. It is therefore pointless to provide as much feedback as possible when it is considered valueless by the receiver. The disinterest by pupils in the teachers' written feedback may be a result of past experiences with other teachers whose comments were recklessly scribbled to just fulfil the education authorities' expectations. Such practices by learners leave the teachers with the necessary and appropriate role to evaluate every written feedback for the pupils to determine whether the pupils have taken heed of the comments. This consideration will not only allow teachers to evaluate pupils' current performance, but also to evaluate the quality of their written feedback on the previous work. This cycle may progressively result in better written feedback by teachers and help in improving or enhancing the future performance of both teachers and pupils.

The Department for Education in England (2017) noted that some schools require their teachers to make extensive comments on every piece of written work given to pupils, and the possibility that some pupils may not even read those comments is worrying. This study therefore seeks to establish the type and quality of written feedback that may impact on students' interest to act on the feedback from the teacher.

\subsection{Effectiveness of Written Feedback}

Feedback is defined by Knight (2016) as authoritative information students receive from the 
teacher, that reinforces or corrects responses to instruction, and guides them more efficiently in attaining the goals of the course. This definition shows that feedback is required to buttress, redress, or reroute children's effort and behaviour in school work. In the same vein, Hattie and Timperley (2007) consider feedback as being significantly influential on learning and academic achievement. Their view implies that feedback and classroom achievement are intertwined and cannot be separated. Written feedback has been identified as assisting learners notice errors in their school work, and that when they notice the mistakes, acquisition of skills of precision is aided (Counselman, 2015). Stephens (2016), hence, asserts that accuracy and skill attainment in the classroom are concerns for both students and teachers. Because of these concerns, most students expect feedback from the teachers because they have an understanding that it is necessary and appropriate to reject and modify conjectures about certain topics (Harmer, 2007). Due to the impact that feedback has on learning in general, different feedback techniques have been investigated, (Hattie \& Timberley, 2007). The following section thus, explains techniques that may improve the effectiveness of written feedback in numeracy at primary school level. According to Kus (2018), numeracy is referred to as quantitative literacy, which involves skills to use numbers and symbols, ability to reason with numbers and use of mathematics to solve real life problems in different contexts. The use of numeracy to solve practical everyday problems implies that numeracy can also be used outside the classroom.

\subsection{Ways to Improve the Quality and Effectiveness of Written Feedback}

Written feedback is considered as a difficult issue in education and can be costly in terms of time for both the teacher and the learners, (Al-Bashir, Kabir \& Rahman, 2016). As such, effort should be invested in ensuring that it is done in the most effective and economic way possible. For feedback to be effective for pupils, they need an understanding of the desired goal, evidence about their present position in relation to that goal and guidance on the way to close the gap between the expected goal and the pupils' actual achievement (Heritage, 2011). This implies that the teachers' feedback should evaluate the pupils' performance, pointing out errors or shortfalls and proffer the way forward in relation to what ought to have been achieved. It would be a waste of time for the teacher to give lengthy comments that will either not be read or be misunderstood by the pupils (The Department for education, 2017).

According to Hattie (2009), feedback needs to be clear, purposeful, meaningful, compatible with students' prior knowledge and provide logical connections. Key issues that can be deducted from the above statement are language or vocabulary used in the feedback, legibility and relevance of feedback to pupils' work. These issues were hinted at in another study by Gardsby and Beere (2012) who hypothesised that when feedback is given in writing, some students have difficulty understanding the points the teacher is trying to make, are unable to read the teacher's writing and cannot process the feedback or understand what to do next. Thus, self-evaluation or self-introspection by the teachers on their feedback to the learners is necessary. According to Clarke (2001), the teachers' comments should be in a language with vocabulary appropriate to the cognitive level of the pupils. Teachers should therefore adapt the language to the aptitude level of the pupils. Since language is at the centre of classroom communication, pupils should be able to decode the feedback and act accordingly. Hattie (2009), hence avows that if feedback is directed at the right level, it can assist pupils to 
comprehend, engage, or develop effective strategies to process the information intended to be taught. This view suggests that it would be futile to spend time giving feedback that would not be understood and would also waste pupils' time as they try to make sense out of it. Nicol (2009) supports the idea when the scholar posits that providing individual comments to students is a highly time consuming activity which may have low benefit if the student does not find the comments helpful. It is therefore necessary that teachers ensure they establish an appropriate level of language in their feedback for their pupils, and put in place two-way feedback mechanisms to ensure that in case of misunderstanding the teacher will know and take remedial action.

Legibility also contributes towards the ability of pupils to decipher meaning from written feedback. Written feedback becomes inconsequent if the pupils cannot read the teacher's feedback in long hand (Gardsby \& Beere, 2012). It is therefore important that the teacher writes legibly so that pupils are able to read the comments.

Besides the challenges and solutions offered in the preceding paragraphs, previous research has established a number of recommendations on how to improve written feedback. A research study by the University of Bristol (2000) concluded that students, who were often confused by effort and attainment grades, occasionally felt that their effort was not recognised by their teachers. They therefore preferred regular, verbal feedback to written feedback at the end of a unit. The same research further proposed that pupils were often unable to act on their teachers' written feedback effectively and felt that constructive feedback helped them to improve their performance. This is supported by a study by Nicol (2009) which posits that teachers' feedback should be non-judgemental and descriptive rather than evaluative or authoritative, and that the feedback should be focused on learning goals and not just performance goals. Nicol's study explains that teachers may be obsessed with grading pupils at the expense of learning goals which may demotivate those with lower grades. This suggestion means that the teachers' feedback should progressively scaffold to bridge the gap between the achieved work and the expected achievement.

South Hunsley School (2013) developed a model for effective written feedback with three elements. Firstly, the feedback statement should contain a positive comment which relates to their achievement of the learning objectives. This should capture what the pupil got right or performed successfully. Secondly, it should offer one way in which improvements could be made, with clear suggestions where appropriate. This should be left unambiguous and should be explicitly spelt out, giving example(s) where applicable. This stage implies that spotting students errors alone without making suggestions for improvement is insufficient. Lastly, one or more open-ended questions should be asked to encourage reflection and further research. According to a study by South Hunsley School (2013), when marked work is returned to pupils, it is imperative to plan time for them to reflect upon the comments and targets, and respond in turn, to the teacher thereby fostering the development of an effective learning relationship. It has been noted in literature, for example, Knight (2016) that written feedback may go unread. Therefore, giving pupils time specifically to go through, reflect and respond to written feedback can go a long way to add value to written feedback and enhance pupil performance. This idea may assist in identifying any challenges that pupils may find with the feedback. These views 
about feedback can be communicated to the teachers for improvement in the future. Adherence to these suggestions could therefore have a double impact on the teaching experiences of a teacher and learning experiences of learners as both the teacher and learners collaborate and improve their respective sides of the process.

\section{Methods}

\subsection{Research Design}

According to the Education and communities Public schools NSW (2018), feedback can only be taken on board by the learners if the teacher provides time, opportunity and support to enact it. The quantitative research method was therefore employed to guide the selection of the quasiexperimental design, based on the one group pre-test post-test approach. The quasiexperimental design allows the determination of an index of change from pre-test to post-test (White \& Sabarwal, 2014). The definition implies that the treatment administered is tested for how well it achieves its objectives as determined by the change of performance in the pre-test and the post-test. In this study, the pre-test post-test design was used to find out how learners respond to and use written feedback in their school work. The independent variable in the study was the teacher feedback whilst the pupils' performance was the dependent variable. The researchers maintained all other factors constant whilst improving their feedback on pupils' work as per the results of the survey answered by the participants.

\subsection{Sampling and Data Collection Procedures}

Purposive sampling was used to collect data from 20 Year 5 students at a primary school in England. The ages of the participants ranged from 9 to 10 years of which 12 were females and 8 were males. A questionnaire was distributed to the participants to determine how they respond to feedback, and what interventions they think can improve written feedback as is currently given by teachers at the School. Subsequent to answering the questionnaire, the researcher taught 'Numeracy' concepts to the students and a written test was given as per the recommendations outlined and explained in the questionnaire answered by the participants. All major and prominent concerns and recommendations made by the participants were addressed and incorporated in the written feedback of the first test. The participants' work was assigned marks out of 20 as per the school marking guide and the same standard was applied to the postintervention evaluation. The participants' scores were not disclosed to them but recorded on a separate schedule to avoid demotivating some of them as suggested by Glasgow and Hicks (2009). To reduce the threat of internal validity, where it would be difficult to conclude with certainty that the observed differences were due to the treatment, the researcher did not prompt the participants to give attention to written feedback, neither were the participants informed that they will write another test, to avoid interfering with the variable under consideration. In addition, no new concepts were taught to the participants related to the questions used in the first test and the teacher used and strictly adhered to the school marking policy. To ensure that the participants were least influenced by other factors such as maturation, which is likely to threaten the internal validity of the findings, (Marsden \& Torgerson, 2012), only two days were 
allowed before the second test was given to allow the pupils time to study the comments and act on them. According to Pyke (2007), familiarity with a test can also sometimes enhance performance because some test items and errors are more likely to be remembered at later testing sessions, especially if the same test is used at pre and post testing. The issue of familiarity, which is likely to affect the internal validity of the results was averted by ensuring that the second test was similar to the first but not the same. To test the impact of the aforementioned interventions of written feedback, the second similar test was given under the same conditions and to the same participants. The timing ensured that all the twenty participants who sat the first test were present to sit the second one. The participants' second test was marked and marks were recorded once more on a schedule for analysis.

\subsection{Data Analysis Procedures}

Descriptive statistics were used to analyse the quantitative data from the structured questionnaire items. The questionnaire items were grouped into related categories and hence, bar charts were used to show the count of the pupils who had certain perceptions of the teacher's written feedback and pupils' understanding of the feedback. Pie charts were also used to describe the frequency of pupils who read the teachers' feedback and the number of pupils who responded to the teacher's written feedback. The measurement of pupils' performance (tests) before and after the feedback intervention were presented and juxtaposed in a table. The results of the tests were then analysed using the t-test. The difference between the two means was tested at $90 \%$ confidence level. According to Littler (2015), a narrower margin of error or a higher confidence level requires a larger sample size. Since the sample in this study is small $(n=20)$, a wider margin of error $(10 \%)$ or lower confidence level $(90 \%)$ was selected, instead of $95 \%$ or $99 \%$. Pseudonyms were used in the study for ethical reasons. However, caution should be taken on generalising the findings of this research as the sample is only a class of one school and may not be reflective of most children of the same age and in various environments.

\section{Results and Discussion of Findings}

\subsection{Reading the Teacher's Feedback}

Figure 1 below answers the question on how often pupils read the teacher's written feedback in their exercise books. 


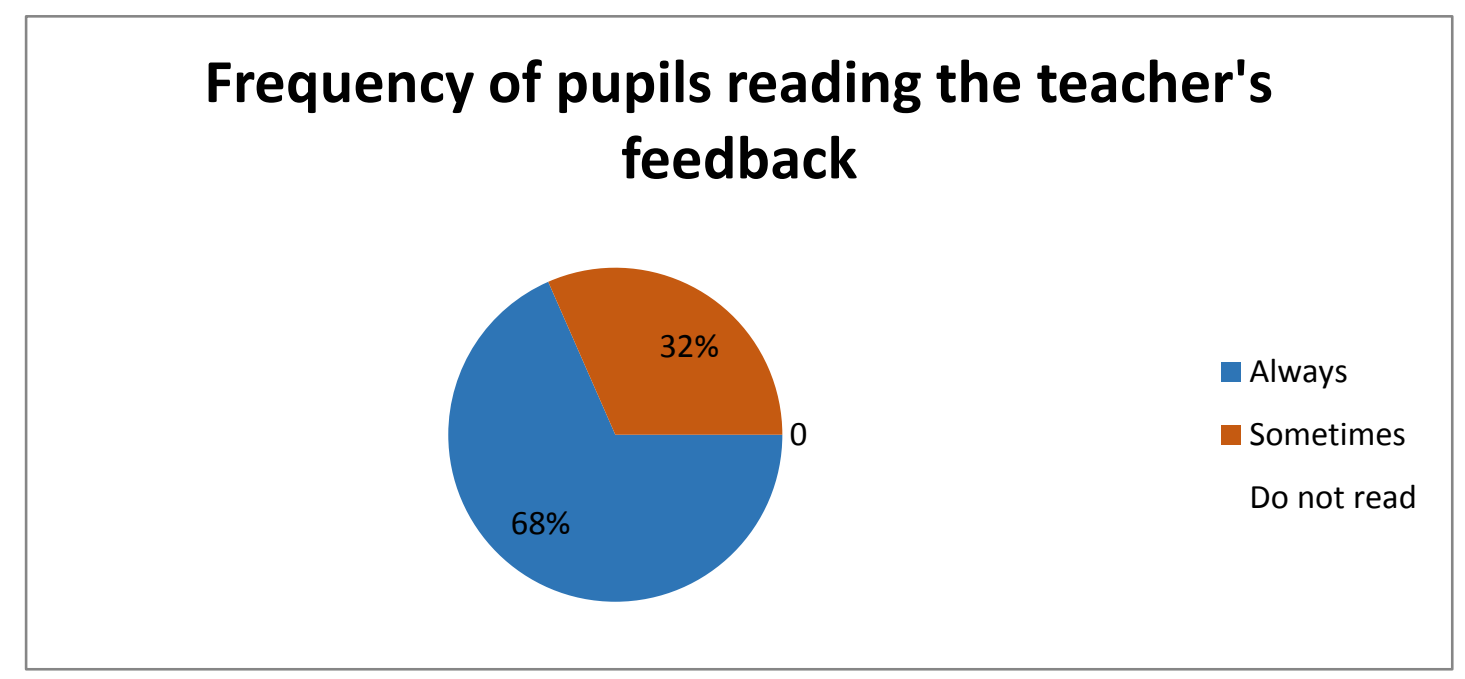

Figure 1. Frequency of Pupils Reading the Teacher's Feedback

From the pie chart above, all pupils seemed to read the teachers' comments at one time or the other. Figure 1 shows that $68 \%$ of the pupils always read the teacher's comments in their books and the dominant reason given by the pupils was for them to make corrections and improve their performance. Of the class, $32 \%$ only read the teacher's comments 'sometimes' because they are in some instances disinterested or simply not in the mood. This practice confirms Knight's (2016) view that some students do not attend to the teachers' comments at all. However, a study by the Education and communities, Public schools NSW (2018) contends that feedback follows instruction. If pupils do not understand completely the concepts taught, they tend to ignore the feedback because they do not understand the feedback either. In such cases, Education and communities, Public schools NSW (2018) recommends that feedback is not usually effective unless further teaching has been done.

\subsection{Usefulness of Written Feedback to Pupils}

What pupils think about written feedback based on the learning experiences can be critical in determining their attitude towards feedback. Knowledge of the pupils' attitudes towards written feedback may assist the teachers to improve their comments in the learners' written work. Figure 2 shows the pupils' perceptions about the usefulness of written feedback. 


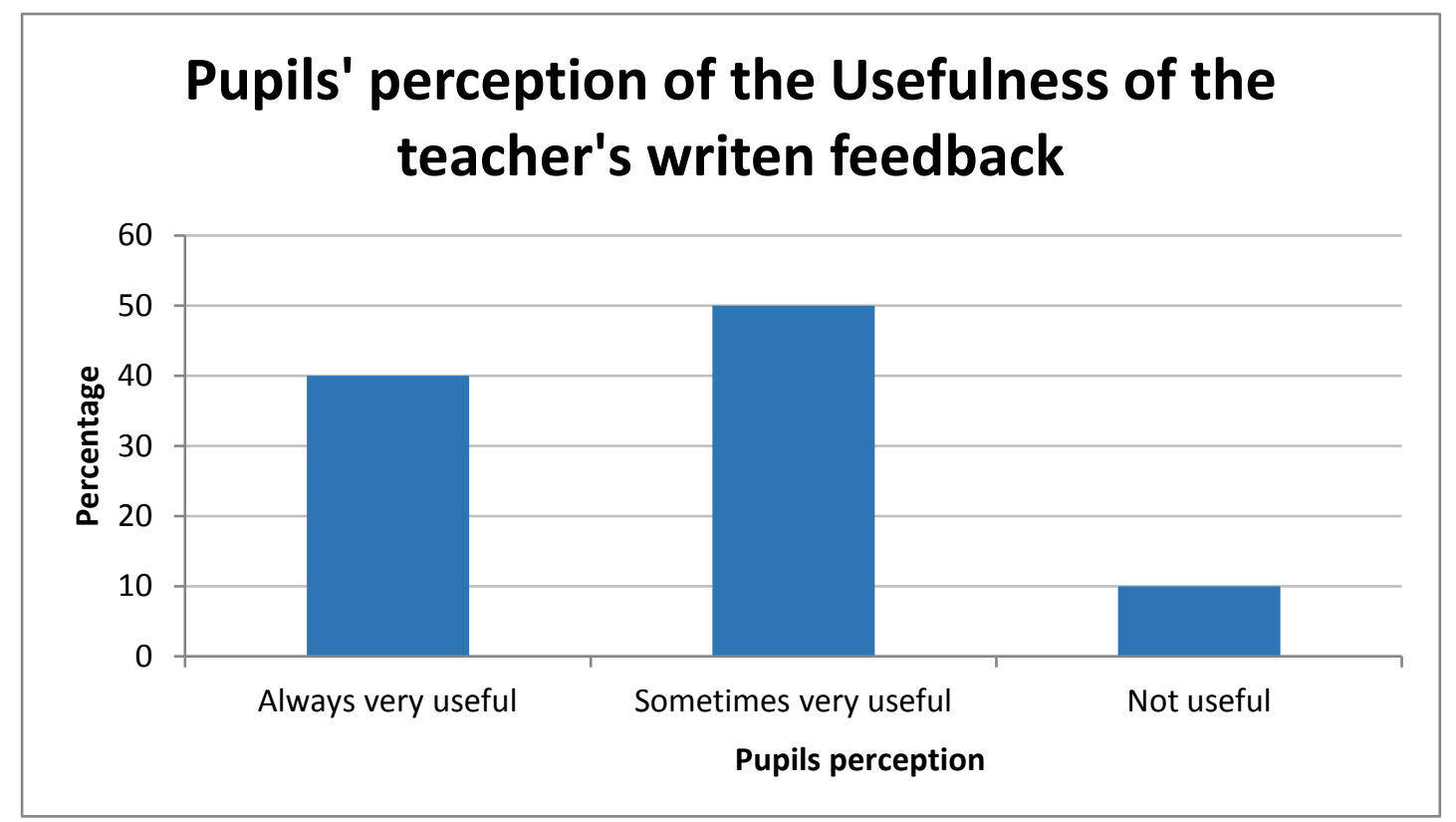

Figure 2. Pupils' Perception of the Teacher's Written Feedback

Pupils who always find feedback useful pointed out that feedback gives them direction, points out their mistakes, and leads them to perform better in the future. The majority however, found issues with teacher feedback. The issues raised by the pupils included that feedback fails to address the pupils' real problems. The pupils pointed out that the feedback given only pinpoints the errors/mistakes made by the learners but the learners could hardly interpret the way forward suggested by the teacher. As a result, some pupils confessed that they read but do not act on the feedback because they do not understand it. Some pupils testified that they just get excited by the comments such as "very good" on their work but do nothing about the work. Other comments like "more effort is called for" were also not meaningful to most of the students because they did not know how to apply the effort. Feedback such as "improve this statement" may leave the learners in a dilemma. Instead, teachers should explain ways in which work can be improved. Effectively, pupils were using the teachers' comments to judge their aptitude level in the classroom rather than enhancing their learning of the subject. For example, someone with an eye catching comment on his/her work would be considered smarter than the one with a somewhat less than positive comment. Hence, Gipps (1994) posits that in order for students to improve in their work, and for learning to be effective, they should have knowledge of the desired standard and then compare their actual performance with the desired performance. This view can constitute quality feedback. Clarke (2001) concurs that quality feedback is the integral factor in improving achievement in mathematics. Glasgow and Hicks (2009) hence, suggest that pupils should receive specific and personal feedback on the results of their practice in order for learning to be effective.

\subsection{Responding to Teacher Feedback}

Figure 3 below shows how pupils use or respond to the teachers' feedback. 


\section{Responding to written teacher feedback}

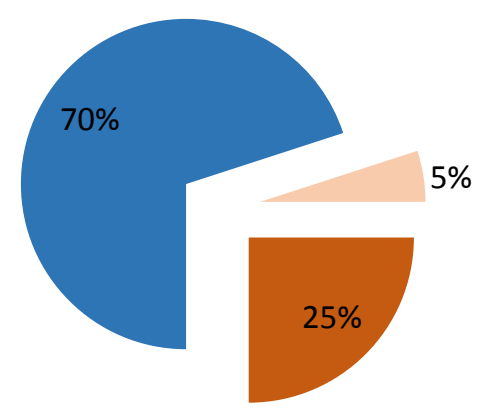

Always

- Sometines

Never

Figure 3. Responding to Written Teacher Feedback

The data above shows that pupils partially and/or totally fail to respond to feedback because they find written feedback difficult to read and understand and that they do not have time to study and understand it. These children's responses are supported by Gardsby and Beere (2012) who highlight that when feedback is given in writing, some students have difficulty understanding the ideas raised by the teacher, are unable to read the teacher's hand writing, cannot process the feedback and cannot understand what to do next. It is natural that individuals can hardly respond to information that they do not understand. Understanding written feedback should therefore be a pre-requisite of responding to it. Hence, Hattie (2009) asserts that feedback needs to be clear and compatible with students' prior knowledge and understanding, for it to be effective.

\subsection{Pupils' Understanding of Teacher Feedback}

Table 1 below illustrates the pupils understanding of the teachers' written feedback.

Table 1. Pupils' Understanding of Teacher Feedback

\begin{tabular}{llll}
\hline Perception of easy/difficulty & $\begin{array}{l}\text { Always easy } \\
\text { to understand }\end{array}$ & $\begin{array}{l}\text { Sometimes easy } \\
\text { to understand }\end{array}$ & $\begin{array}{l}\text { Always difficult } \\
\text { to understand } \\
7 \text { Frequency (\%age) }\end{array}$ \\
$15 \%$ & $75 \%$ & $10 \%$ \\
\hline
\end{tabular}

Data in Table 1 show that the bulk of the pupils do not fully understand the feedback given by teachers. This could explain the reason why some pupils see no significant value of written feedback, as it is shown in section 4.2 of this study. In addition, comparison of data in Figure 3 and Table 1 shows that there is a striking sync between responding to the teachers' feedback and pupils' understanding of the feedback. This implies that if pupils do not understand the 
feedback given, they do not respond to the feedback. This idea resonates with that of Heritage (2012) who explains the cause effect relationship between understanding and response to feedback. Figure 4 below shows the reasons why some pupils fail to understand teachers' written feedback.

\subsection{Factors Making the Teachers'Feedback Difficult to Understand}

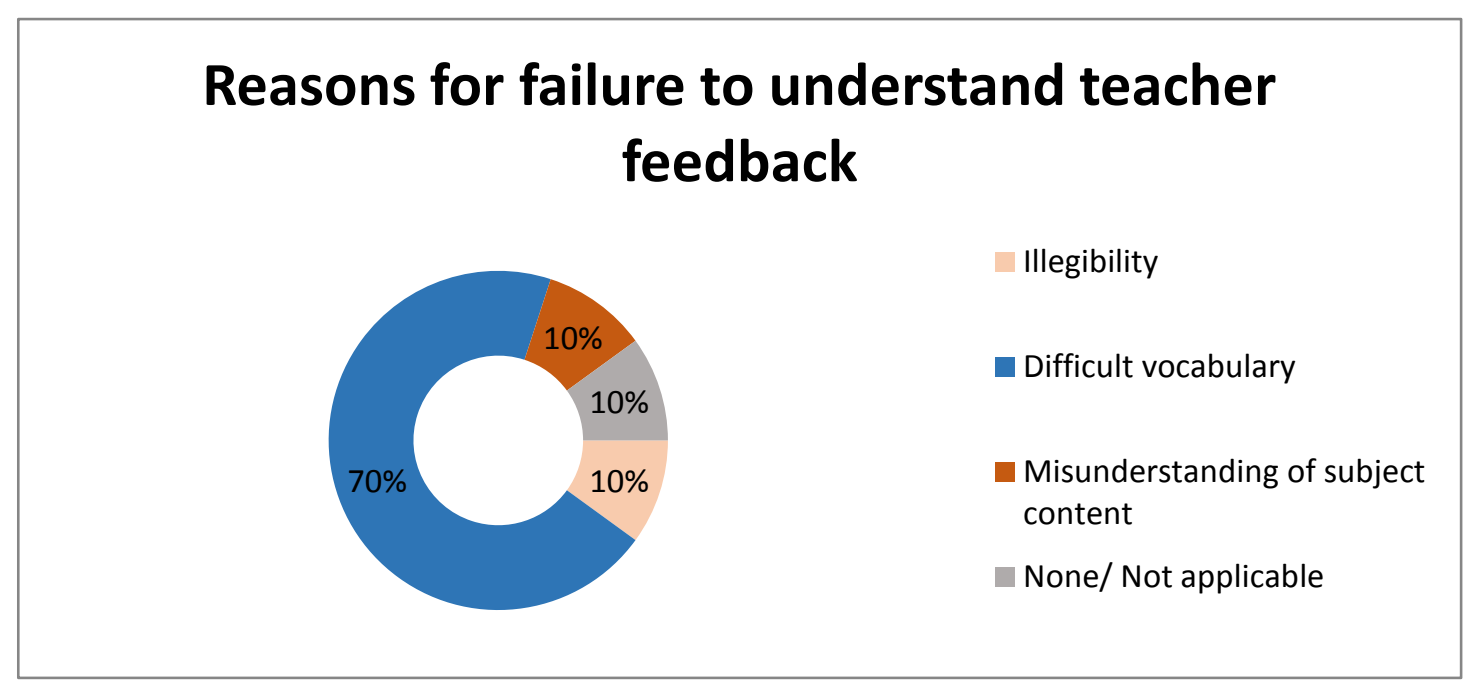

Figure 4. Reasons Why Pupils Do not Understand the Teachers' Feedback

As a follow up to data in Table 1, the participants confirmed that teachers' feedback was difficult to understand. When asked to state the reasons why comprehending the feedback was difficult, the large majority of the pupils (70\%) cited unfamiliar vocabulary, as the major cause of their failure to understand the teachers' feedback. This factor is followed by illegibility of the teachers' comments and misconception of the subject content. The findings are compatible with Garder's (2012) assertion that the level of comprehension of language used in the feedback and legibility of the feedback determine the pupils' understanding of feedback. According to Clarke (2003), Gardsby and Beere (2012) and Glasgow and Hicks (2009), one of the most important elements bearing on the usefulness of the teachers' feedback is language. This view shows that there is amazing convergence between literature and the findings of this study (Section 4.4 and 4.5). As Garder (2012) advises on this issue, teachers have to think critically and be more meticulous in framing comments so that pupils understand and receive appropriate guidance in order to improve practice. Furthermore, research by Van der Schaaf et al (2013) claims that if feedback is directed at the right level, it can assist students to comprehend, engage, or develop effective strategies to process the information intended to be learnt.

\subsection{Measurement of Pupil Performance before and after Feedback Intervention}

The results of the two tests given prior to and after written feedback are recorded in Table 2 below. The objective was to determine the effectiveness of the feedback given. 
Table 2. Results of the Two Tests

\begin{tabular}{lcc}
\hline Pupil & Mark before intervention & Mark after intervention \\
\hline 1 & 11 & 15 \\
2 & 16 & 14 \\
3 & 12 & 12 \\
4 & 13 & 15 \\
5 & 7 & 13 \\
6 & 15 & 16 \\
7 & 10 & 12 \\
8 & 13 & 11 \\
9 & 12 & 13 \\
10 & 9 & 13 \\
11 & 13 & 9 \\
12 & 10 & 15 \\
13 & 9 & 8 \\
14 & 6 & 11 \\
15 & 15 & 17 \\
16 & 14 & 13 \\
17 & 10 & 14 \\
18 & 12 & 16 \\
19 & 8 & 10 \\
20 & 11 & 11 \\
Total & 226 & 255 \\
\hline
\end{tabular}

Table 3 below shows an analysis of the two sets of data (tests) that were collected before and after the feedback intervention.

Table 3. $t$-test Report

\begin{tabular}{lll}
\hline & Set A Data & Set B Data \\
\hline $\mathbf{N}$ & 20 & 20 \\
Mean $\left(\boldsymbol{\mu}_{\mathbf{1}}, \boldsymbol{\mu}_{\mathbf{2}}\right)$ & 11.3 & 12.9 \\
Standard Deviation (SD) & 2.72 & 2.43 \\
$\mathbf{t}$ - experimental & & 1.965 \\
$\mathbf{p}$ (type 1 error) & & 0.0568 \\
\hline
\end{tabular}

Notes $^{*}$ : Set A Data - Data before intervention, Set B Data-Data after intervention

$\mathrm{H}_{0}: \quad \mu_{1}=\mu_{2}$

$\mathrm{H}_{1}: \quad \mu_{1} \neq \mu_{2}$ 
Since the $p$-value $=0.0568<0.1$, we reject $\mathrm{H}_{0}$ and conclude that at $10 \%$ level of significance, there is insufficient evidence to say that the first mean $\left(\mu_{1}\right)$ is equal to the second mean $\left(\mu_{2}\right)$.

The t-test result shows that at the $90 \%$ confidence level, there is a significant difference between the two means. The difference can be attributed to the feedback intervention as all other factors were held constant. This shows that the interventions conducted of improving the quality of feedback using the participants' suggestions can help children address their targets, which consequently enhances achievement of learning goals by the pupils. It should however be noted that out of the 20 participants in this study only 4 , constituting $20 \%$, recorded a decline in performance after intervention. Two pupils (10\%) maintained the same scores before and after intervention. The researchers considered these as outliers given that $70 \%$ had their scores increasing showing a better comprehension of the concepts as explained and clarified to them through written feedback. This result has implications that involvement of learners in suggesting types of comments convenient for their learning, contributes to the construction of quality feedback for achievement in numeracy. Hence, the Ofsted Inspection Report (2018) acknowledged written feedback as interplay between teacher and learner, and making decisions about what teachers and learners need to do. It would be a waste of time giving feedback that is not comprehensive for learners, as indicated in section 4.5 .

\section{Conclusion and Recommendations}

\subsection{Conclusion}

The findings of this study show that written feedback is a key aspect of teaching and that if effectively applied, enhances achievement, as exhibited in section 4.6 of this study. Table 2 of section 4.6 revealed improvement in performance after inculcating the pupils' suggestions in the feedback to the first test. Their improvement in the second test shows that the pupils read and understood the feedback. Hence, understanding the given feedback can be regarded as the pupils' back bone of appreciating and enacting the feedback in their work to achieve learning goals. The study shows that pupils sometimes do not respond to the feedback because they do not understand it. The misconception of feedback in the study was attributed to illegibility and unfamiliar vocabulary in the teachers' comments, (section 4.5). Vocabulary is also cited in literature by Absolum (2006), Clarke (2003) and Heritage (2011) as impacting the quality of written feedback. The scholars' findings indicate that for written feedback to be understandable by the pupils and effectively achieve its intended goals, the language should be adapted to the cognitive level of learners, to ensure the message is received and ultimately acted upon (Clarke, 2005). Overall, the study concludes that learners need to understand the feedback first. When they understand, they are able to appreciate the usefulness of the feedback. Appreciation of the worthiness of the feedback may then lead to responding and acting upon it (sections 4.2, 4.3, 4.4). The findings of the study also show that effective feedback can be a catalyst to student's achievement in numeracy as shown in Section 4.6. In table 2, the two means were significantly different, which shows the impact of the feedback intervention. 


\subsection{Recommendations}

Based on the findings of the study, it is recommended that teachers should adapt their language to the aptitude levels of pupils when giving written feedback and avoid using words that may not be familiar to pupils. Otherwise, responding to feedback can remain a mammoth task if pupils fail to understand the feedback ( $4.3 \& 4.4)$. For feedback to be of value to the pupils' learning experiences, it should provide the way forward towards the desired outcome. Explanations of where exactly have been done wrong and examples, should be given as a guide to the desired outcome where applicable. Comments like "more effort is needed" might fail to stipulate what pupils are exactly supposed to do in order to realise the effort and to achieve learning goals. From section 4.5, pupils had several reasons why they were failing to understand teacher feedback. Teachers should therefore, be able to understand the needs of each pupil through experience with the class so that they assist the pupils accordingly.

\section{Acknowledgement}

This paper is part of the bigger study of my unpublished dissertation: Mutendi, M. (2016). How is written feedback given in children's written work responded to and used by children in the core group in my year 5 Class to help them address targets to make progress in learning? Faculty of Education, Bishop Grosseteste University. England.

\section{References}

Absolum, M. (2006). Clarity in the classroom. Auckland: Hodder Education.

Al-Bashir, M. M., Kabir, M. R., \& Rahman, I. (2016). The Value and Effectiveness of Feedback in Improving Students' Learning and Professionalizing Teaching in Higher Education. Journal of Education and Practice, 7(16), 38-41.

Brown, P. (2001). Assessment: A Guide for Lecturers. LTSN Generic Centre Assessment Series No.3, York: LTSN.

Clarke, S. (2001). Unlocking Formative Assessment; Practical Strategies for Enhancing Pupils' Learning in the Primary School. London: Hodder Arnold.

Clarke, S. (2003). Enriching Feedback in the Primary Classroom. Hodder and Stoughton: London.

Clarke, S. (2005). Formative Assessment in Action; Weaving the Elements Together. Hodder Education: London.

Conn, J. J. (2002). What can Clinical Teachers learn from Harry potter and the Philosopher's stone? Medical Journal, 36, 1176-1181. https://doi.org/10.1046/j.13652923.2002.01376.x

Counselman, D. (2015). Directing attention to pronunciation in the second language classroom. Hispania, 98(1), 31-46. https://doi.org/10.1353/hpn.2015.0006

Department for Education. (2017). Reducing teacher workload (Marking policy). Retrieved from https://www.gov.uk/government/publications/reducing-teachers- 
workload/reducing-teachers-workload

Education and communities, Public schools NSW. (2018). Practices that promote feedback Strong start, Great teachers Phase 3. Retrieved from ww.ssgt.nsw.edu.au/documents/2practices_feedback.pdf

Educational Endowment Foundation (2016). Responding to Feedback. Retrieved from https://educationendowmentfoundation.org.uk/news/eef-marking-review-responding-tofeedback/

Ferguson, P. (2011). Student perceptions of quality feedback in teacher education. Assessment \& Evaluation in Higher Education, 36(1), 51-62. https://doi.org/10.1080/02602930903197883

Garder, J. (2012). Assessment and Learning. (2nd ed.). London: Thousand Oaks.

Gardsby, C., \& Beere, J. (2012). Perfect Assessment for Learning. Wales: IndependentThinking Press.

Gibbs, G., \& Simpson, C. (2002). How assessment influences student learning - a literature review (draft). Student Support Research Group. Milton Keynes: Open University.

Gipps, C. V. (1994). Quality in Teacher Assessment. In W. Harlen, (Ed.), Enhancing Quality in Assessment. (pp.71-86). London: Paul Chapman Publishing.

Glasgow, N. A., \& Hicks, C. D. (2009). What Successful Teachers Do: 101 Research-Based Classroom Strategies for New and Veteran Teachers. Carlif: Corwin Press.

Harmer, J. (2007b). How to teach English (New Edition). England: Pearson Education Limited. Hattie, J. (2009). Visible Learning. London and New York: Routledge.

Hattie, J., \& Timperley, H. (2007). The power of Feedback. Review of Educational Research, 77(1), 81-112. https://doi.org/10.3102/003465430298487

Heritage, M. (2011). Formative Assessment: Making it happen in the Classroom. Thousand Oaks: Calif.

Higher Education Funding Council for England, (2011). The National Student Survey: Findings and Trends, 2006-2010. Bristol: Higher Education Funding Council for England.

James, R., Krause, K. L., \& Jennings, C. (2010). The First Year Experience in Australian Universities: Findings from 1994-2009. Melbourne: Centre for Higher Education Studies: University of Melbourne.

Knight, N. (2016). An evaluation of the quality of teacher feedback to students. A study of numeracy teaching in the primary education sector. Retrieved from $\mathrm{http}$ ://educationgroup.co.nz/wp-content/uploads/2016/04/An-evaluation-of-the-qualityof-teacher-feedback-to-students.pdf

Kus, M. (2018). Numeracy. Brock Education Journal, 27(2), 58-62. https://doi.org/10.26522/brocked.v27i2.579.

Littler, S. (2015). The Importance and Effect of Sample Size. Retrieved 23 March 2019 from https://select-statistics.co.uk/blog/importance-effect-sample-size/

Marsden, E., \& Torgerson, C. J. (2012). Single group, pre-post-test research designs: Some methodological concerns. Oxford Review of Education, 38(5), 583-616. https://doi.org/10.2307/41702779 
Murphy, C., \& Cornell, J. (2010). Student perceptions of feedback: seeking a coherent flow. Practitioner research in higher education, 4(1), 41-51.

Nicol, D. (2009). McKeachie's Teaching Tips: Strategies, Research, and Theory for College and University Teachers (13th Ed). New York: Houghton Mifflin.

Nicol, D. (2010). From monologue to dialogue: improving written feedback processes in mass higher education. Assessment \& Evaluation in Higher Education, 35(5), 501-517. https://doi.org/10.1080/02602931003786559

Ofsted Inspection Report (2018). Myths. Retrieved from https://www.gov.uk/government/publications/school-inspection-handbook.

Orrella, J. (2006). Feedback on learning achievement: rhetoric and reality. Teaching in Higher Education, 11(4), 441-456. https://doi.org/10.1080/13562510600874235

Pyke, R. O. C. (2007). Assessment Practices in Curriculum Materials Research: Do Students Learn from the Pretest? Paper presented at the Annual Meeting of the American Educational Research Association Chicago, IL April 10-14, 2007. The George Washington University.

South Hunsley School (2013). Generic marking and feedback policy. Retrieved from http://www.southhunsley.org.uk/uploads/generic/Marking_and_Feedback_Policy__June_2013.pdf

Stephens, C. (2016). The Effectiveness of Using Written Feedback to Improve Adult ESL Learners' Spontaneous Pronunciation of English Suprasegmentals. Brigham Young University BYU Scholars Archive. Retrieved from https://scholarsarchive.byu.edu/etd/6062

University of Bristol. (2014). Regulations and Code of Practice for Taught Programmes: Rules for Assessment, Progression and the Award of a Qualification 2013-14.

Van der Schaaf, M., Baartman, L. K., Prins, F. J., Oosterbaan, A. E., \& Schaap, H. (2013). Feedback dialogues that stimulate students' reflective thinking. Scandinavian Journal of Educational Research, 57(3), 227-245. https://doi.org/10.1080/00313831.2011.628693

White, H., \& Sabarwal, S. (2014). Quasi-experimental design and methods: methodological briefs, impact evaluation No. 8. Unicef Office of Research, Innocenti. Retrieved from http://www.unicef-irc.org/publications/753/

\section{Copyright Disclaimer}

Copyright for this article is retained by the author(s), with first publication rights granted to the journal.

This is an open-access article distributed under the terms and conditions of the Creative Commons Attribution license (http://creativecommons.org/licenses/by/3.0/). 